\title{
Effect of milk fat content on the viscoelasticity of mozzarella-type cheese curds
}

\author{
Hiroyuki Shima · Morimasa Tanimoto
}

Received: date / Accepted: date

\begin{abstract}
The effect of fat content in cheese curds on their rheological properties were examined using dynamic shear measurements. Surplus fat addition to milk samples caused two distinct types of changes in the temperature dependence of the viscoelastic moduli of resultant curds. The first was a significant reduction in the moduli over a wide temperature range, which is attributed to the presence of liquefied fat globules within the milk protein network. The second was the excess contribution to the low-temperature moduli owing to the reinforcing effect of solidified fat globules. An upward shift in the sol-gel phase transition temperature driven by an increased fat content was also observed.
\end{abstract}

Keywords Cheese rheology · Protein network · Sol-gel phase transition · Lipid globule $\cdot$ Dynamic shear modulus

\section{Introduction}

Fat and protein are the two primary components in raw milk. The fat content of bovine milk is nearly $4 \%$ by weight, and it is dispersed in milk serum as globules with diameters that range from $0.2 \mu \mathrm{m}$ to $15 \mu \mathrm{m}$, c.a. $4 \mu \mathrm{m}$ on average 11. Similar to fat globules, casein proteins (i.e., the major class of milk protein) exist as colloidal particles, known as casein micelles, and have diameters that range from $50 \mathrm{~nm}$ to $500 \mathrm{~nm}$ (average $120 \mathrm{~nm}$ ). These colloidal domains comprise almost 80 $\%$ of the total solid content in milk. Therefore, their structural stability and interparticle interactions strongly affect the quality of dairy products such as cheese,

Hiroyuki Shima

Department of Environmental Sciences, University of Yamanashi, 4-4-37, Takeda, Kofu, Yamanashi 400-8510, Japan

Tel.: +81-55-2208834

Fax: +81-55-2208834

E-mail: hshima@yamanashi.ac.jp

Morimasa Tanimoto

Department of Local Produce and Food Sciences, University of Yamanashi, 4-4-37, Takeda, Kofu, Yamanashi 400-8510, Japan 

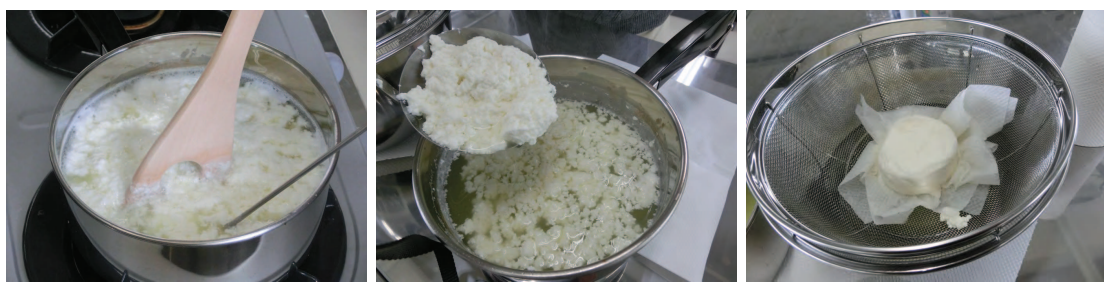

Fig. 1 Left: Initiation of milk clotting obtained just after adding rennet. Middle: Curd granules. Right: Final state from which all whey is removed.

yoghurt, and butter. In particular, the presence of fat in cheese is necessary to develop the characteristic flavour profile and favoured mouth-feel.

The production of natural cheese is initiated by the addition of rennet to milk. The rennet-induced proteolysis of the surfaces of casein micelles leads to their aggregation, resulting in a three-dimensional protein network. The network exhibits non-uniform viscoelasticity in accordance with changes in the temperature, $\mathrm{pH}$, and protein concentration 2, 3. Cavities in the network are filled with fat globules and some whey; the total mixture of these materials comprises a cheese curd. Many fat globules in the curd remain stored, even after curd syneresis is completed, and they contribute to the desirable functional properties of the final cheese product. In fact, artificial removal of fat from the curd causes quality degradation, leading to a firm and dry cheese that melts poorly [4. Toward quality improvement, numerous studies have focused on the effect of fat content or its reduction in cheese. Despite consumer enthusiasm for fat-free diets, these attempts have met with limited success [5,6,7]. A better understanding of the interplay between fat globules and the protein network is indispensable for developing a solution.

Aside from the practical motivation, it is also interesting from an academic perspective to explore the effects of fat content on the rheology of cheese curds. An important feature of fat globules, which contribute to curd rheology, is the wide variety in in size and melting temperature. The broad distribution of fat globule sizes allows them to interact with cheese microstructures in multiple ways. Large fat globules are likely to disrupt a portion of the protein network and suppress direct cross-linking between protein threads. Hence, if they are liquefied, large globules are expected to plasticize adjacent protein threads [8], yielding a structurally loose matrix with reduced firmness. In contrast, small globules tend to occlude the fine empty spaces in the network $[9$ and are thought to act as reinforcing fillers [10 if they are in solid phase. However, a simple explanation of the temperature dependence of the fat content may be insufficient owing to the wide variety of fat melting points. There is not a sharp difference between the liquid and solid states of fat globules in curds. A single fat globule encloses many kinds of triglyceride isomers with different melting points [11,12, and thus the solidity and fluidity of the globule are determined by the relative proportion of isomers. The actual melting temperature ranges from $-40^{\circ} \mathrm{C}$ to $40^{\circ} \mathrm{C}$, between which crystalline and liquid fat coexist in curd [13. It remains unclear how the two competing roles of fat globules, as plasticizers and reinforcing fillers, are manifested with respect to thermal-induced changes in cheese curd rheology.

In the present study, we address the effect of fat content and $\mathrm{pH}$ control on the viscoelastic moduli of rennet cheese curds. The $\mathrm{pH}$ control allows us to examine the 
effects of fat content under various structural conditions of the protein network. High $\mathrm{pH}$ conditions cause protein networks to become weaker and more porous. In contrast, low $\mathrm{pH}$ conditions result in network contraction, in which either or both of the effects as plasticizers or fillers may be enhanced. To verify our conjecture, we performed dynamic shear tests and measured the variation in the temperature dependence of the moduli with changes in $\mathrm{pH}$. Particular emphasis was paid to the rheological behaviours below $20{ }^{\circ} \mathrm{C}$ and above $50{ }^{\circ} \mathrm{C}$, wherein most fat globules are solidified and liquefied, respectively.

\section{Material and method}

\subsection{Preparation of sample milk}

Figure2 displays a flow chart summarizing the production of $\mathrm{pH}$ - and fat-controlled cheese curds. Raw milk was obtained from the Kiyosato Milk Plant located at the foothills of Mount Yatsugatake, Japan. To assess the effects of fat content on cheese rheology, two classes of fat-adjusted milk were prepared. Skim milk was produced with a fat content of less than $1 \%$ by weight. Fat-enriched milk was produced by adding $1 \mathrm{~kg}$ of fresh cream with $47 \%$ fat into $17 \mathrm{~kg}$ of raw milk with $3.8 \%$ fat. The fat-enriched milk contained $6.2 \%$ fat by weight. Each milk sample $(18 \mathrm{~L})$ was first pasteurized by maintaining the sample at $65^{\circ} \mathrm{C}$ for $30 \mathrm{~min}$. This process eliminates bacteria, thus preventing the degradation of milk proteins at high temperatures. After pasteurization, the samples were then cooled to $31^{\circ} \mathrm{C}$. The sample $\mathrm{pH}$ was 6.65 at this stage, and was directly determined using an electrode-type $\mathrm{pH}$ meter (SK-620PH, skSATO, Tokyo, Japan).

\subsection{Starter insertion}

Milk acidification was triggered by adding $18 \mathrm{~mL}$ of a Lactobacillus culture solution to the milk sample. The culture solution was a mixture of $0.3 \mathrm{~g}$ of Direct Vat Set (DVS) Lactobacillus starter (CHN-11, Chr. Hansen, Nosawa \& Co., Ltd., Tokyo, Japan) with $300 \mathrm{~mL}$ of pasteurized milk that was prepared in advance. After adding the culture solution, the sample was maintained at $31{ }^{\circ} \mathrm{C}$, which is the temperature that produces the optimal Lactobacillus activity, for $30 \mathrm{~min}$. The sample $\mathrm{pH}$ at this stage was 6.50.

\subsection{Cheese curd production}

Rennet was then added to the above sample that was slightly acidified by lactobacilli. In this experiment, $0.5 \mathrm{~g}$ of rennet (CHY-MAX, Chr. Hansen, Nosawa \& Co., Ltd.) dissolved in sterile cold water was added to the sample, which was then maintained at $31{ }^{\circ} \mathrm{C}$ for $30 \mathrm{~min}$. After the milk started to coagulate, the sample was cut into cubes of $12 \times 12 \times 12 \mathrm{~mm}^{3}$ to remove a portion of whey from the curds. After cutting, the sample was gently agitated for 5 min to encourage the removal of whey. As a result, whey corresponding to one-third of the original 


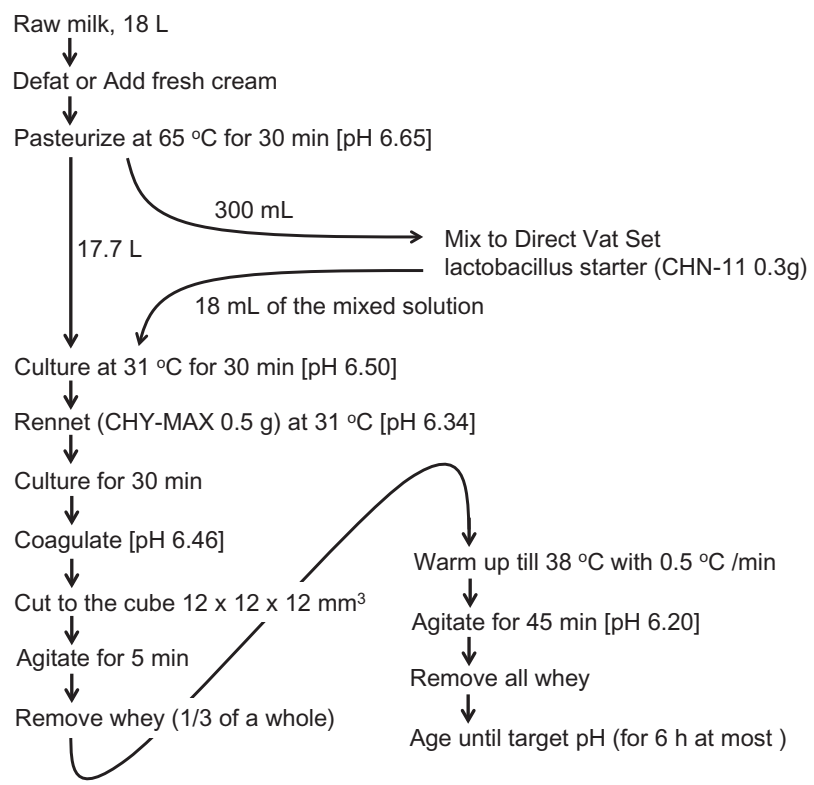

Fig. 2 Flow chart of mozzarella-type cheese curd production.

sample weight was eliminated, yielding two classes of curd granules that differed in fat content.

To complete the whey removal process, hot water was added gradually to the curd granules so that the sample temperature increased at a rate of $0.5^{\circ} \mathrm{C} / \mathrm{min}$. When it reached $38^{\circ} \mathrm{C}$, the granules were gently agitated again for $45 \mathrm{~min}$; eventually, all whey was removed. In the final step, the curds were aged until they reached the target $\mathrm{pH}(4.8-5.7)$. The time required to attain curds with the lowest $\mathrm{pH}$ was approximately $6 \mathrm{~h}$. After $\mathrm{pH}$ adjustment, a series of curds with different $\mathrm{pH}$ values were frozen and stored. Immediately before measurement, the curds were defrosted in a refrigerator and then stirred at $50-60{ }^{\circ} \mathrm{C}$.

\subsection{Composition analysis}

The chemical composition of the fat-controlled curds is summarized in Table 1 . For both no-fat and high-fat samples, the highest $\mathrm{pH}$ among the samples examined are displayed, as well as the analysis method. It is noteworthy that the amount of fat was supressed to $2.7 \mathrm{~g} / 100 \mathrm{~g}$ in the no-fat sample, while it increased to 30.1 $\mathrm{g} / 100 \mathrm{~g}$ in the high-fat sample. The ratios of calcium to protein are presented in the bottom row of Table 1 and indicate that fat control has no effect on the calcium content within the protein network.

\subsection{Dynamic shear measurement}

Viscoelastic moduli of the cheese curds and their dependence on $\mathrm{pH}$, temperature, and fat content were evaluated by small-amplitude oscillatory shear tests. 
Table 1 Chemical compositions of the obtained curds with different fat contents. $\left({ }^{*} \mathrm{ICP}=\right.$ Inductively Coupled Plasma)

\begin{tabular}{lrrc}
\hline & No-fat & Hi-fat & Method of analysis \\
\hline $\mathrm{pH}$ & 5.60 & 5.70 & pH meter \\
Fat $(\mathrm{g} / 100 \mathrm{~g})$ & $\mathbf{2 . 7}$ & $\mathbf{3 0 . 1}$ & Acid hydrolysis method \\
Protein $(\mathrm{g} / 100 \mathrm{~g})$ & 38.8 & 16.3 & Kjeldahl method \\
& & & \\
Moisture $(\mathrm{g} / 100 \mathrm{~g})$ & 53.1 & 48.2 & Atmospheric heating drying method \\
Ash (g/100g) & 3.7 & 1.7 & Direct ashing method \\
$\mathrm{P}(\mathrm{g} / 100 \mathrm{~g})$ & 0.805 & 0.346 & ${ }^{*} \mathrm{ICP}$ atomic emission spectroscopy \\
$\mathrm{Ca}(\mathrm{g} / 100 \mathrm{~g})$ & 1.23 & 0.502 & same as above \\
Ratio Ca/Protein $\left(\times 10^{-2}\right)$ & 3.17 & 3.08 & \\
\hline
\end{tabular}

These are non-destructive tests for determining the viscoelasticity of a material [14 15], and have been widely used for analysing cheeses and other foodstuff such as chocolates [16] and rice bran [17.

Specifically, an oscillatory shear strain is applied to the sample at constant frequency of $1 \mathrm{~Hz}$ and a constant strain amount of $0.1 \%$, which satisfies the linear viscoelastic condition. Decreasing the temperature from $65{ }^{\circ} \mathrm{C}$ to $5{ }^{\circ} \mathrm{C}$ was carried out in a ramp fashion with a constant cooling rate of $2{ }^{\circ} \mathrm{C} / \mathrm{min}$. The observed quantities were the temperature $(T)$ dependences of the elastic (or storage) modulus, designated $G^{\prime}(T)$ and the viscous (or loss) modulus, $G^{\prime \prime}(T)$. The former is a measure of the elastic energy stored per oscillation cycle; plainly stated, this parameter indicates the degree to which the sample gives a solid-like response to the dynamic load. The latter is a measure of the energy dissipated as heat per cycle, and indicates the degree to which a sample shows liquid-like behaviour.

Empirical measurements were performed using a rheometer (Anton Paar MCR 302). The samples were thinly sliced and sandwiched between two flat disk plates with a $25 \mathrm{~mm}$ radius, facing each other, separated by a gap of $2 \mathrm{~mm}$. The sample surface was coated with silicone oil to prevent evaporation of water during measurements. After coating the sample, it was gradually cooled, during which $G^{\prime}$ and $G^{\prime \prime}$ were measured by applying the oscillatory shear. From the $G^{\prime}$ and $G^{\prime \prime}$ data, the loss tangent $\tan \delta \equiv G^{\prime \prime} / G^{\prime}$ was also evaluated for each temperature and $\mathrm{pH}$ condition.

\section{Result I: Plasticizer effect and reinforcing effect}

Figure 3 shows single-logarithm plots of $G^{\prime}(T)$ and $G^{\prime \prime}(T)$ for samples under different $\mathrm{pH}$ conditions. The measured data for the no-fat and high-fat samples are plotted in Fig. 3(a) and Fig. 3(b), respectively. For each pH condition, 10 samples were analysed and only minor sample dependence was detected. Based on the figure, the quasi-static cooling of the samples from $60{ }^{\circ} \mathrm{C}$ (or slightly above) to $5{ }^{\circ} \mathrm{C}$ causes exponential increases in the magnitude of both $G^{\prime}(T)$ and $G^{\prime \prime}(T)$. This rigidity enhancement driven by slow cooling is attributed to the disappearance of thermally excited vibrations in the constituents. By cooling the samples, the degree of thermal vibration in the protein threads as well as fat globules is depressed and local detachment between protein threads becomes difficult. As a result, the samples get firmer as the temperature decreases, consistent with our 

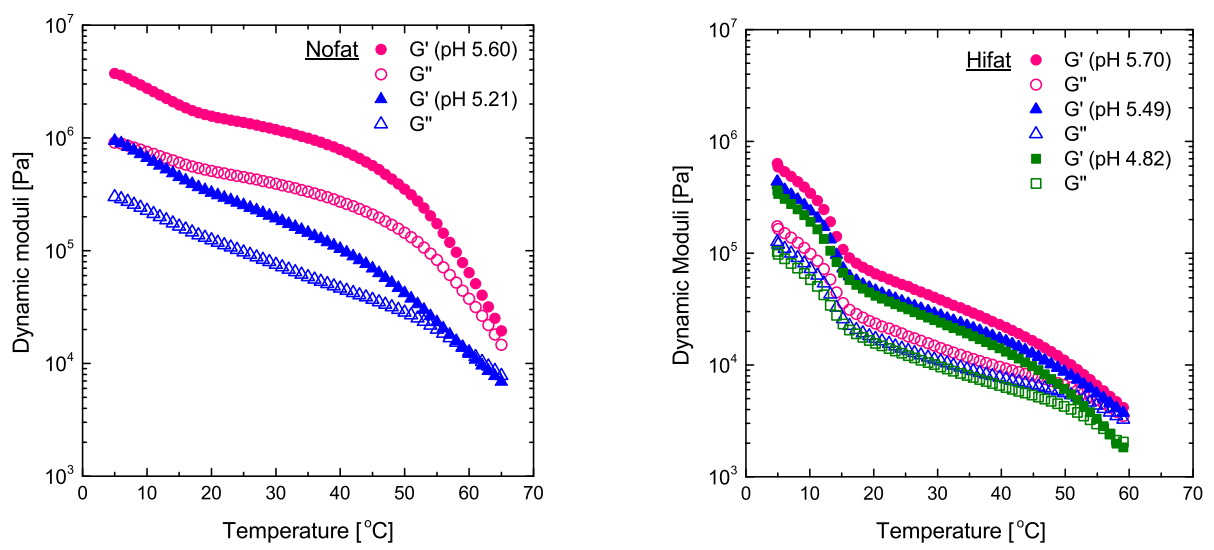

Fig. 3 Temperature dependence of the dynamic moduli of curds under different pH conditions. (a) The no-fat sample; (b) The high-fat sample.

observations in our daily life. This rigidity enhancement seems to be universal for all $\mathrm{pH}$ conditions and fat contents.

An effect of fat-control on the magnitudes of $G^{\prime}(T)$ and $G^{\prime \prime}(T)$ was clear, when we compared the high-fat data with the no-fat data presented in Fig. 3. At every $T$ and $\mathrm{pH}$, the moduli for the high-fat samples are nearly one order of magnitude smaller than those for the non-fat samples. This fat-induced reduction in the moduli is explained by the plasticizer effect of fat globules. The globules tend to fill in the voids of the protein network or get between the protein threads. The insertion of the fat globules into voids or gaps between protein threads keep them further apart and reduce the forces of attraction between the threads, thus making the whole curd more flexible. Such a plasticizer effect (as well as a possible mechanical cushion effect) is pronounced at moderately high temperatures $\left(>20^{\circ} \mathrm{C}\right)$ because a large portion of the fat in the globules melts and becomes deformable. Furthermore, the plasticizer effect is enhanced at a relatively large $\mathrm{pH}(\sim 5.60-5.70)$, as the protein network is rather sparse and accordingly involves numerous voids into which fat globules can penetrate.

Another important consequence of the fat addition to the raw milk was a rapid growth in the low-temperature moduli with cooling. As shown in Fig. 3(b), below $20{ }^{\circ} \mathrm{C}$, the moduli rapidly increase with cooling for every $\mathrm{pH}$. This rapid growth in the moduli results from the solidification of fat globules in the protein matrix. Below $20{ }^{\circ} \mathrm{C}$, the solid domain of the fat pooled in the globules gradually increases with cooling; as a result, they begin to function as reinforcing fillers. A similar reinforcing effect has been observed in our previous study 18, in which the viscoelastic moduli of cheese curds free from fat control were examined. In the no-fat data shown in Fig. 3(a), the reinforcing effect disappears almost completely, and there is only a slight change in the slope of the moduli curves at approximately $20{ }^{\circ} \mathrm{C}$ owing to the minimal fat content in the skim milk.

In short, we identified the temperature ranges within which fat globules act as plasticizers and/or reinforcing fillers. The plasticizing effect was observed over the whole temperature range $\left(5^{\circ} \mathrm{C}-60{ }^{\circ} \mathrm{C}\right)$, reducing both the moduli of $G^{\prime}(T)$ and $G^{\prime \prime}(T)$ for the high-fat samples. The reinforcing effect was observed only below 

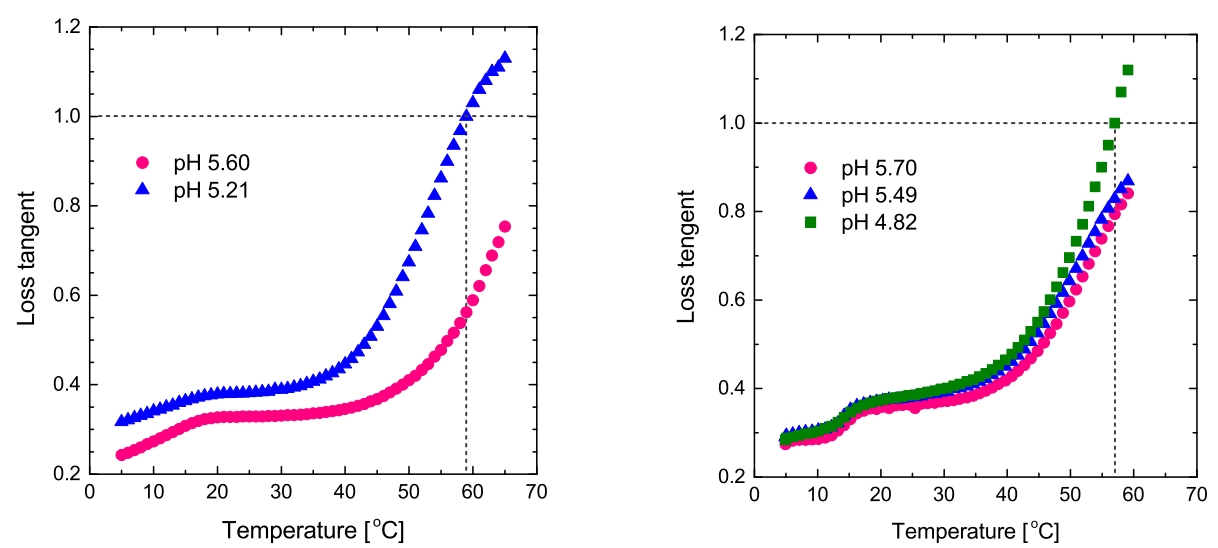

Fig. 4 Temperature variance of the loss tangent $\tan \delta$ for: (a) the no-fat case, and (b) the high-fat case. The sol-gel transition temperature $T_{C}$ above which $\tan \delta$ exceeds unity is marked by dotted lines.

$20^{\circ} \mathrm{C}$, leading to an excess contribution of the low-temperature moduli of the highfat samples. The identification of these temperature ranges was the first main result of the present work.

\section{Result II: Sol-gel structural phase transition}

Figure 4 shows the $T$-dependences of the loss tangent, $\tan \delta$, for the fat-controlled and pH-regulated samples in the same way as those in Fig. 3. For both high-fat and no-fat samples, the loss tangent exceeds unity at the following temperature ranges: $T>59^{\circ} \mathrm{C}$ for the no-fat case with $\mathrm{pH} 5.21$ and $T>57^{\circ} \mathrm{C}$ for the high-fat case with $\mathrm{pH}$ 4.82. The high temperature ranges showing $\tan \delta>1$ indicates a structural transition from a sol phase (liquid state) to a gel phase (solid state) 19 , 20, above which the curds react to an external stress in a more viscous and fluidic, less elastic manner [21. The heat-induced flowability is believed to result from higher molecular mobility and reduced cross-linkage within the casein network 22. These two (and potentially other) physicochemical factors promote molecular alignment parallel to the tensile direction, enhancing the flow of the cheese curds at temperatures that satisfy $\tan \delta>1$. The sol-gel transition demonstrated in Fig. 4 is consistent with the thermal softening of the casein network in fully coagulated mozzarella cheese reported in the literature 23. Using the squeezing flow method, it has been reported that mozzarella cheese shows a decreased resistance to flow as the temperature increases; the relaxation time of mozzarella cheese was reduced by several-fold as the temperature increased from $30{ }^{\circ} \mathrm{C}$ to $60{ }^{\circ} \mathrm{C}$, corresponding to a monotonic decrease in $G^{\prime}(T)$ and $G^{\prime \prime}(T)$ with increasing $T$ (see Fig. 3).

It is interesting to examine how the $\mathrm{pH}$ and fat content affect the sol-gel phase transition temperature $T_{C}$. First, sufficient acidification is required to observe the sol-gel transition. Reducing the $\mathrm{pH}$ promotes the dissociation of calcium ions from the bonding parts of protein molecules. Hence, the network becomes looser, yielding feasible flow rates above $T_{C}$. In our high-fat condition, for instance, the sample at $\mathrm{pH} 4.82$ undergoes the transition at $T=57^{\circ} \mathrm{C}$, whereas no transition 
occurs for larger $\mathrm{pH}$ values. In the no-fat condition, a $\mathrm{pH}$ of 5.21 suffices for samples to go through the transition at $T=59^{\circ} \mathrm{C}$. Second, the value of $T_{C}$ decreases as the fat content decreases. Indeed, our previous study has shown that $T_{C}=43^{\circ} \mathrm{C}$ for the sample free from fat-control for a $\mathrm{pH}$ of 4.8. Additionally, based on Fig. 4 (a), for no-fat samples with $\mathrm{pH} 4.8, T_{C}$ is close to or less than that for fat-control-free samples. The fat-induced reduction in $T_{C}$ (for a fixed $\mathrm{pH}$ ) indicates the consistent adhesion property of fat globules to the protein matrix. Since liquefied globules that are soft and deformable tend to maintain adhesion to surrounding protein molecules, adjacent protein threads are glued and cannot break apart. If the fat content decreases, the gluing mechanism is suppressed and the gel phase is favoured at moderately high temperatures. This explains why $T_{C}$ values for the natural-fat and no-fat samples are smaller than that of the high-fat samples.

In short, we revealed the effect of fat content on the sol-gel transition temperature $T_{C}$. The addition of excess fat to raw milk results in an upward shift of the $T_{C}$ of cheese curds due to the adhesion property of fat globules to protein threads. This is the second main result of the present article.

\section{Conclusion}

We investigated the effect of fat content variation on dependences of $G^{\prime}(T)$ and $G^{\prime \prime}(T)$ on $T$ for mozzarella-type cheese curds. We observed two distinct effects. Specifically, we detected a fat-induced reduction in the moduli (i.e., the plasticizing effect) at all temperatures between $5^{\circ} \mathrm{C}$ and $60{ }^{\circ} \mathrm{C}$, and a fat-induced excess contribution to the moduli (i.e., the reinforcing effect) that is observable only below $20^{\circ} \mathrm{C}$. The former effect is attributed to the presence of liquefied fat globules wrapped around the three-dimensional protein network, which reduce the attractive forces between the threads, making the system more flexible. With additional cooling, in contrast, a portion of fat pooled in the globules becomes solidified and begins to function as a reinforcing filler; this results in the latter effect. In addition to these two effects, we revealed the fat-induced reduction in the critical temperature $T_{C}$ for the sol-gel phase transition of the cheese curds. This increase in $T_{C}$ indicates the adhesion property of liquefied fat globules to protein threads.

Acknowledgements The authors express their gratitude to Emeritus Prof. Ryoya Niki, Prof. Katsuyoshi Nishinari, Prof. Kaoru Sato, and Mr. Kunio Ueda for fruitful discussions and technical supports. This work was supported by JSPS KAKENHI Grant Numbers 25390147 and 25560035

Conflict of interest None.

Compliance with Ethics Requirements This article does not contain any studies with human or animal subjects.

\section{References}

1. M.C. Michalski, M. Ollivon, V. Briard, N. Leconte, C. Lopez, Chemistry and Physics of Lipids 132, 247 (2004)

2. A. Al-Nabulsi, R. Shaker, T. Osaili, S. Clark, F. Harte, G. Barbosa-Cánovas, International Journal of Food Properties 15, 613 (2012) 
3. I. Catarino, A.P.L. Martins, E. Duarte, E.S. Prudêncio, M.N. de Pinho, Journal of Food Engineering 114, 249 (2013)

4. V.V. Mistry, International Dairy Journal 11, 413 (2001)

5. J.M. Banks, International Journal of Dairy Technology 57, 199 (2004)

6. J.L. Childs, M. Drake, Journal of Sensory Studies 24, 902 (2009)

7. S. Skeie, G. Alseth, H. Ostlie, R. Abrahamsen, A. Johansen, J. Oyaas, International Dairy Journal 33, 153 (2013)

8. D.E. Johnston, Journal of Dairy Research 51, 91 (1984)

9. M.C. Michalski, B. Camier, V. Briard, N. Leconte, J.Y. Gassi, H. Goudédranche, F. Michel, J. Fauquant, Lait 84, 343 (2004)

10. N. Desai, J. Nolting, Book: Chemistry of StructureFunction Relationships in Cheese, edited by E.L. Malin and M.H. Tunick, New York: Plenum Press. (1994)

11. R.G. Jensen, A.M. Ferris, C.J. Lammi-Keefe, Journal of Dairy Science 74, 3228 (1991)

12. C. Lopez, Reproduction Nurtition Development 45, 497 (2005)

13. G.M. Pilhofer, H.C. Lee, M.J. McCarthy, P.S. Tong, J.B. German, Lait 77, 55 (1994)

14. S. Gunasekaran, M.M. Ak, Trends in Food Science and Technology 11, 115 (2000)

15. M.H. Tunick, Journal of Agricultural and Food Chemistry 59, 1481 (2011)

16. K. van der Vaart, F. Depypere, V.D. Graef, P. Schall, A. Fall, D. Bonn, K. Dewettinck, European Food Research and Technology 236, 931 (2013)

17. Y. Zhang, L. Huang, Z. Wei, European Food Research and Technology 239, 971 (2014)

18. H. Shima, M. Tanimoto, International Journal of Food Properties tba, DOI:10.1080/10942912.2014.978009 (2015)

19. C.Y.M. Tung, P.J. Dynes, Journal of Applied Polymer Science 27, 569 (1982)

20. S.B. Ross-Murphy, Journal of Texture Studies 26, 391 (1995)

21. T. van Vileta, P.Z. S.P.F.M. Roefs and, P. Walstra, Journal of Dairy Research 56, 529 (1989)

22. S. Mleko, P. Janas, J. Pielecki, Journal of Food Science and Technology 42, 58 (2005)

23. M. Ak, S. Gunasekaran, Journal of Texture Studies 26, 695 (1996) 


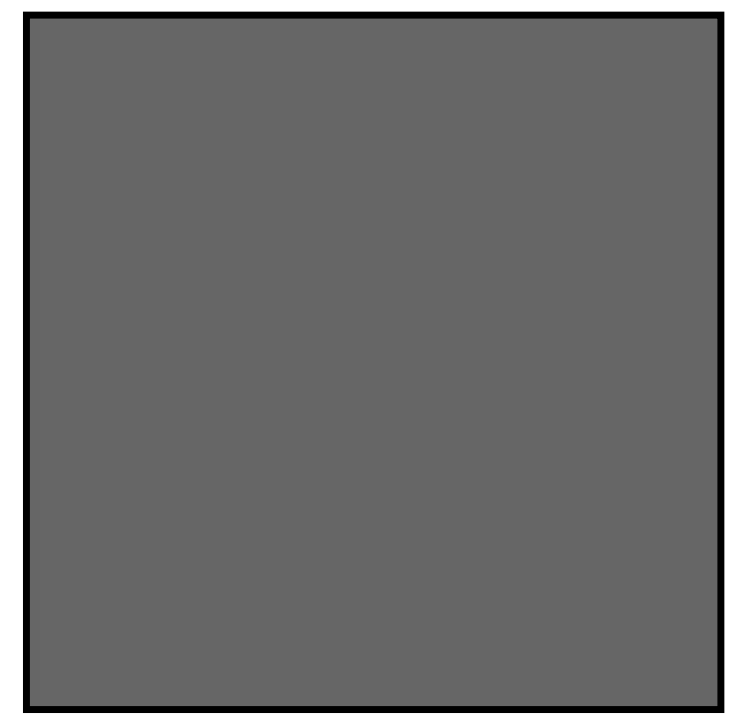

